\title{
Attitudinal Determinants of diet and lifestyle among African and Caribbean women living in the UK : study design and rationale
}

\section{Diets of African and Caribbean women}

Amanda R Amorim Adegboye ${ }^{1}$, PhD

Amanda P Moore ${ }^{2}$, MSc

Stefania Comegna ${ }^{3}$, MSc

Ihab Tewfik ${ }^{3}, \mathrm{PhD}$

Alizon Draper ${ }^{3}, \mathrm{PhD}$

Gulshanara Begum ${ }^{3}$, PhD

1. School of Human Sciences, Faculty of Education, Health and Human Sciences, University of Greenwich. Old Royal Naval College. Park Row. London. SE10 9LS. UK

2. Departments of Nutrition \& Diabetes, Faculty of Life Sciences \& Medicine, King's College London, Franklin Wilkins Building, Stamford Street, London SE1 9NH. UK

3. School of Life Sciences, University of Westminster. New Cavendish Street. London W1W 6UW. UK

Corresponding Author: Dr Amanda R Amorim Adegboye

The University of Greenwich. Dreadnought building.

Old Royal Naval College. Park Row. London. SE10 9LS

Phone: 02083318064 | E-mail: A. Adegboye@greenwich.ac.uk 


\section{Abstract}

The aim of this article is to describe the rationale and design of a cross-sectional study that investigated the influence of attitudinal factors on diet and lifestyle of African and Caribbean women living in the UK. The results of the study will be presented elsewhere. African and Caribbean women are at high risk of obesity which exacerbates health inequalities. In the UK, little work has been carried out to better understand attitudinal factors that contribute towards obesity, lifestyle and health practice amongst this group.

Methods: The study applied a comprehensive questionnaire to capture socio-demographic data and explore general attitudes towards diet and lifestyle of African and Caribbean women. Dietary data were collected using triple-pass 24-hour recalls. In addition, all participants had anthropometric measures, blood pressure and biochemical indices assessed using standardised methods.

Discussion: Potential strengths and limitations of the current study design, exploring health, diet, and lifestyle habits and the contextual influence on these practices among African and Caribbean in the UK are discussed. Findings from this study will contribute to the understanding of food and health practices, the role of socio-cultural factors and potential barriers and facilitators to the adoption of a healthy lifestyle, which could reduce the risk of cardiovascular disease, obesity, and type 2 diabetes, all of which have increased prevalence in these communities.

Keywords: African, Caribbean, Culture, Diet, Women, Lifestyle,

\section{Acknowledgements}

The authors acknowledge the investigators, volunteers, faith and community leaders and participants of the study for their support and enthusiasm.

The study was funded by the University of Westminster.

Amanda Moore is supported by the National Institute for Health Research (NIHR) Collaboration for Leadership in Applied Health Research and Care South London at King's College Hospital NHS Foundation Trust. The views expressed are those of the author[s] and not necessarily those of the NHS, the NIHR or the Department of Health and Social Care.

\section{Conflict of Interest}

No conflicts of interest to report.

\section{Authors' contribution}

Research concept and design: ARAA, GB

Training and data collection: ARAA, AM, SC, GB

Data entry: AM, SC

Data cleaning and preliminary data analysis: ARAA, AM

Manuscript draft and revision: ARAA, AM, SC, IT, GB

Administrative: ARAA, GB

Supervision: ARAA, GB 


\section{Introduction}

The purpose of this article is to detail the rationale behind a cross-sectional study designed to investigate attitudinal determinants of diet and lifestyle among African and Caribbean women living in the United Kingdon (UK). The UK population is becoming gradually more diverse, with 73\% of population growth coming from the Black and Minority Ethnic (BME) groups (Office for National Statistics (ONS), 2012). West-African and Black-Caribbean ethnic groups make up around $3 \%$ of the UK population and the majority of these groups are clustered in London (ONS, 2012).

African and Caribbean (AfC) women have the highest obesity prevalence (38\% and 32\%, respectively) among all ethnic groups in the UK (Gatineau \& Mathrani, 2011). BME groups experience both poorer physical and mental health compared to the host population and they are at high risk for obesity-related health problems, which include diabetes, cardiovascular diseases and hypertension (Health Survey for England (HSE), 2006). Although the National Health Services (NHS) provides a range of healthcare services free to UK residents, evidence points to persisting socioeconomic and ethnic inequity in healthcare use (Szczepura, 2005). While differences in socioeconomic status (SES) are the major contributor to ethnic health inequalities, SES may not explain all variations in the health status of BME groups (Chowbey \& Harrop, 2016).

In general, women face particular weight-related risks to their health as a result of their reproductive and caring roles. Becoming a parent appears to worsen the eating habits of mothers, but not fathers (Berge, Larson, Bauer, \& Neumark-Sztainer, 2011). Women with young children tend to consume more calories than non-mothers (Berge et al., 2011). Furthermore, pregnancy-associated weight gain and failure to lose weight subsequently may contribute to the development of obesity (Amorim, Rössner, Neovius, Lourenço, \& Linné, 2007). Multi-ethnic and low-income women are not only more likely to retain weight following pregnancy and develop chronic diseases themselves (Siega-Riz et al., 2010), but their health behaviour may also play an important role in shaping the lifestyle of the family and subsequent generations (Gibson et al., 2007).

There is no straightforward relationship between obesity and ethnicity and a complex set of psychosocial, geneticand contextual factors may influence body weight in minority groups (Gatineau \& Mathrani, 2011; Gilbert \& Khokhar, 2008). These include limited access to safe places to exercise, stress related to migration and settlement, low-pay and long working hours and change in food habits due to acculturation within the new host country (Gilbert \& Khokhar, 2008; Leung \& Stanner, 2011; Smith, Kelly, \& Nazroo, 2012)-

There are few studies in the literature regarding cultural influences and valuations driving standards of ideal and current body weight, particularly among women (Bhuiyan, 2003). A previous study shows that overweight body size, though not obesity, is generally seen as positive among African women (Holdsworth, Gartner, Landais, Maire, \& Delpeuch, 2004), and this has critical implications for prevention and education programs among these groups, as positive attitudes towards overweight body size may interfere women's risk awareness and willingness to control their weight.

Health behaviour is influenced by beliefs, perceived susceptibility, self-efficacy and sociocultural norms (Holdsworth et al., 2006) and these factors vary across different communities (Howard, Hugo, Taylor, \& Wilson, 2008). Cultural heritage has been shown to influence 
beliefs and perceptions about body image, healthy eating and physical activity (Howard et al., 2008). Normative beliefs (beliefs about other people's approval for one's behaviour) and selfrepresentation (how people define themselves in the context of others), degree of cultural affiliation, migration status, degree of integration and acculturation, religiosity, generational differences, and level of health literacy are likely to play a role in the dietary and lifestyle habits of AfC women (Smith et al., 2012). Understanding these influences on health behaviour will allow healthcare practitioners to better support patients via designing targeted approaches or programmes specific to the community, aimed at effective behavioural change (Fernandez, Ruiter, Markham, \& Kok, 2019).

Tailoring lifestyle interventions and care to be sensitive to cultural habits and beliefs is a key public health recommendation (Archibald, 2011) . Furthermore, culturally tailored care has been shown to improve outcomes (Joo \& Liu, 2019). However, little work has been carried out to better understand attitudinal factors that contribute towards obesity, lifestyle and health practice amongst UK African and Caribbean communities. The aim of designing this study was to gather data to enable a better understanding of these factors in order to inform the development of culturally salient care and interventions to best support these, at risk, communities in the UK. The study design highlighted herein is an important first step to increase understanding within this community to best support positive health behaviours.

\section{Methods}

\section{Study Design}

The ATTITUDE study applied a quantitative approach, based on a cross-sectional survey, to investigate attitudinal factors influencing diet, physical activity, and body weight in AfC women living in the UK. It was particularly focused on knowledge, beliefs, and selfperceptions related to diet, exercise and body image. The primary and secondary objectives of this study are described in Table 1.

\section{Target population and recruitment}

Adult women self-ascribed as Black African or Caribbean living in London were eligible for the study. Women who had any severe medical condition or disability that significantly influenced their dietary and physical activity behaviours were excluded from the study. Pregnant women, lactating women, women with less than six weeks postpartum or cognitively or physically unable to take part were not eligible.

The sample was self-selected but an element of purposeful sampling was employed to support maximum diversity in terms of age and ethnicity. Participants were recruited across London with a particular focus on the London Boroughs (Croydon, Greenwich, Enfield, and Lewisham) with a high population density of the target ethnicities. Participants were recruited directly into the study via advertisements, flyers, and posters distributed across community venues, churches, and university campuses and via liaison with church leaders, emails and social media. Women were also opportunistically recruited (face-to-face) from community settings (faith-based institutions, community centres and libraries). Snowballing sampling was also applied. 
Table 1. Objectives of the ATTITUDE study

\begin{tabular}{|c|c|}
\hline Primary & Secondary \\
\hline $\begin{array}{l}\text { - To understand what attitudes and } \\
\text { beliefs shape dietary intake and } \\
\text { engagement in physical activity among } \\
\text { AfC women. }\end{array}$ & $\begin{array}{l}\text { To describe the distribution of known } \\
\text { or suspected risk factors associated } \\
\text { with obesity and related diseases. }\end{array}$ \\
\hline $\begin{array}{l}\text { - To understand how the country of origin } \\
\text { and length of UK residence influence } \\
\text { dietary intake and the contribution that } \\
\text { traditional foods make to the diet. }\end{array}$ & $\begin{array}{l}\text { To explore the influence of social status, } \\
\text { religious affiliation and number of family } \\
\text { members on food purchases and dietary } \\
\text { intake. }\end{array}$ \\
\hline \multirow[t]{4}{*}{$\begin{array}{l}\text { To investigate the differences in } \\
\text { understanding and use of the front } \\
\text { of pack (FOP) nutrition labelling } \\
\text { between the } 1^{\text {st }} \text { and } 2^{\text {nd }} \text { generation } \\
\text { of women in the UK. }\end{array}$} & $\begin{array}{l}\text { To investigate any relationships between use } \\
\text { of FOP nutrition information and biochemical } \\
\text { indices, anthropometric measures, and dietary } \\
\text { intake.. }\end{array}$ \\
\hline & $\begin{array}{l}\text { - To assess biochemical indices (TC, HDL-C, } \\
\text { LDL-C, TG, and plasma glucose); } \\
\text { anthropometric measures (BMI, \% body fat, } \\
\text { waist-to-hip ratio) and physiological } \\
\text { parameters (blood pressure and resting heart } \\
\text { rate) in a subset of the study population }\end{array}$ \\
\hline & $\begin{array}{l}\text { - To investigate the correlation between } \\
\text { body image perception, current BMI and } \\
\text { cultural identity among AfC women. }\end{array}$ \\
\hline & $\begin{array}{l}\text { - To compare the BMI and physical } \\
\text { activity levels between women with and } \\
\text { without children }\end{array}$ \\
\hline
\end{tabular}

AfC, African and Caribbean; BMI, body mass index; FOP, front of pack; HDL-C, highdensity cholesterol; LDL-C, low-density cholesterol; TC, total cholesterol; and TG, triglycerides

\section{Data collection and sample size}

To address the aims, data collection was organized into three phases: I) survey, II) additional biochemical indices, anthropometric and physiological measures for a proportion of willing participants who completed the survey (health screen) and III) dietary assessment for same participants in phase II. Data collection was completed in October 2017. 
According to the Cochran sample size formula (Bartlett II, Kotrlik, \& Higgins, 2001) for a 5point scale variable, it was estimated that with an alpha level of 0.05 and $5 \%$ margin of error, a sample size of 267 would be required to achieve statistical validity. Taking into account incomplete data (approximately 10\%), the recruitment target for the survey was sent to a minimum of 300 participants. Regarding the dietary assessment, the recruitment target was based on the sample size used in previous studies. Studies using dietary recall data typically ranged from a minimum of 50 (Goff, Timbers, Style, \& Knight, 2015) up to 150 (Blissett \& Bennett, 2013) participants. It was estimated that a sample of at least 100 women would allow an accurate assessment of dietary patterns. The same sample size was applied for the health screen.

\section{Phase I}

This phase included self-completion of a pre-piloted online survey $(n=307)$, designed in Qualtrics software (Qualtrics, Provo, UT) primarily distributed via social media, study website, email and quick response (QR) code in flyers and posters. Reminder emails were sent biweekly (a total of three reminders after the initial email invitation). The online survey was tested on iPhones, androids, desktops using different software and hardware configurations. The online version of the survey was also piloted for operational and typological errors. A paper-based survey was available upon request. Data obtained from manual completion of the surveys were entered by the research team into the survey software tool to generate a collective dataset for data analysis.

The online survey included an introductory text, informed consent, and three binary eligibility questions: 1) Are you female? 3) Are you aged between 18 and 65 years? and 3) Are you of Black British, Black African or Black Caribbean ethnicity? The survey included 83 questions, which were subdivided into six sections 1) demographic data (including migrant history), self-rated health and SES; 2) diet-related knowledge and attitudes; 3) shopping and understanding and use of food labels; 4) body weight and body image and shape; 5) physical activity, and 6) cultural affiliation and religion. To avoid excess missing data in the section located towards the end of the questionnaire, sections appeared at random order and only section 1 was fixed. As part of the survey, participants were given the opportunity to indicate whether they would like to take part in the health screen (phase II) and dietary assessment (phase III). Details about the sections in the survey are described in Table 2.

\section{Phase II}

A subsample of participants who completed the survey also took part in a health screen $(\mathrm{n}=$ 122). These participants were self-selected, either responding to the online questionnaire or to recruitment advertisements and posters. The biochemical indices (health screen) included measurements of lipids (high-density cholesterol (HDL-C), low-density cholesterol (LDL-C) and triglycerides (TG)), non-fasting plasma glucose, blood pressure, resting heart rate and anthropometric data. Anthropometric data were collected in accordance with standardized procedures (Centres for Disease Control and Prevention, 2007) which includes: weight (kg), height $(\mathrm{m})$, body mass index $(\mathrm{BMI})$, waist and hip circumferences $(\mathrm{cm})$, waist-to-hip ratio and percentage of body fat (\%BF). The \%BF was measured using bioelectrical impedance analysis (BIA) (Tanita Total Body Composition Analyzer, TBF-300). BMI was calculated as weight/height $\left(\mathrm{kg} / \mathrm{m}^{2}\right)$ and blood pressure was measured using a validated digital monitor (Omron HBP-1300)(Meng et al., 2016), prior to blood sampling. 
Table 2. List of survey variables

\begin{tabular}{|l|l|}
\hline \multicolumn{1}{|c|}{ Survey sections } & \multicolumn{1}{c|}{ Variables } \\
hocio-demographic and & $\begin{array}{l}\text { Age, date of birth, country of birth, year of arrival in the UK and } \\
\text { migration history, birth country of parents and grandparents, civil } \\
\text { status, type of household, number of children, employment status, } \\
\text { occupation of the main income provider in the household, } \\
\text { education, self-rated health and any confirmed diagnoses of } \\
\text { diseases. }\end{array}$ \\
\hline Diet & $\begin{array}{l}\text { Self-rated diet quality, food choice, attitudes towards healthy } \\
\text { eating, knowledge of healthy eating, dietary self-efficacy, barriers } \\
\text { and motivators to healthy eating and consumption of dietary } \\
\text { supplements. }\end{array}$ \\
\hline $\begin{array}{l}\text { Shopping and food } \\
\text { labelling }\end{array}$ & $\begin{array}{l}\text { Use of front of food packaging (FOP), use of the back of food } \\
\text { packaging (BOP); understanding of FOP, preference of types of } \\
\text { FOP, type of information read in FOP and BOP, factors } \\
\text { influencing food purchase and frequency of take-away } \\
\text { consumption. }\end{array}$ \\
\hline $\begin{array}{l}\text { Body image and weight } \\
\text { status }\end{array}$ & $\begin{array}{l}\text { Body satisfaction, body image picture and body perception scale, } \\
\text { knowledge of healthy body weight, and self-reported weight and } \\
\text { height. }\end{array}$ \\
\hline Physical Activity (PA) & Barriers and motivators to PA, leisure PA, and occupational PA. \\
\hline Culture & $\begin{array}{l}\text { Language spoken at home, cultural affiliation and identity, } \\
\text { religious affiliation, frequency of attendance of places of worship } \\
\text { and importance of the place of worship in social life. }\end{array}$ \\
\hline
\end{tabular}

BOP, back of food packaging; FOP, front of pack; PA, physical activity

The health screen data collection was performed within churches, community centres and university premises by the lead researchers and a team of trained under- and postgraduate students. The biochemical indices were assessed using finger-prick blood samples using a portable analyser (CardioChek, PA). After completion of the data collection, participants were asked if they wanted to be informed about their results and a leaflet with general information on a healthy lifestyle and feedback regarding their results were provided.

\section{Phase III}

Habitual dietary intake was estimated using the standardized triple-pass 24h recall methodology (Nelson, Holmes, \& Roberts, 2013) in a subsample $(n=122)$ of the study population who took part in the survey (Phase I) and health screen (Phase II). The lead researchers were trained in administering this methodology and a series of two or three recalls were taken. Prior to the data collection, a comprehensive list with the most common foods consumed by West-Africans and Black-Caribbean and mode of preparation was created. The researchers also attended cooking demonstrations to get familiar with African and Caribbean traditional cuisine. The first recalls were completed face-to-face and the subsequent ones by telephone. At least one weekend day and one weekday were included to ensure the capture of maximum dietary variation. Participants were asked to indicate their portion sizes using a photographic food atlas, and household measures (Nelson, Atkinson, \& Meyer, 1997). Information about brand and portion sizes were collected for pre-packaged and processed foods. Recipes and methods used for cooking (e.g. frying, roasting, steaming, etc.) 
were recorded for home-prepared foods. Participants were given a $£ 10$ gift voucher on completion of the final recall.

\section{Ethical considerations}

Consent was sought from venues that agreed to host data collection and from women who agreed to take part in the study. Participants' data were anonymised using a unique reference number. Participants were given an information sheet when they were informed about the study. Data were stored on University premises and are password protected. The coding key for participants was stored separately from the data so there is no possibility of linking the two. Ethical approval was granted by the University of Westminster ethics committee under reference VRE1415-1345.

\section{Analytical plan}

Dietary intake will be coded and analysed using Nutritics Software (Nutrics, 2018). If any food items are not available within the database, a new entry will be generated, especially for homemade recipes. A 'West African Food Composition Table' will be used to find the nutritional composition information (Stadlmayr et al., 2012). The distribution of macronutrient intake in the sample population will be obtained, as well as a calculation of fibre intake and non-starch polysaccharides. Potential under-reporting will be assessed using age- and sex-specific standard equations used to estimate Basal Metabolic Rate (BMR) based on the measured weight of participants (Frankenfield, Roth-Yousey, \& Compher, 2005). The caloric contribution (in percentage) that traditional foods make to nutrient intakes in the AfC women will be calculated.

A new UK Nutrient Profiling Model (NPM) which reflects current UK dietary recommendations will be to classify 'healthy' and 'less healthy' foods and drinks (PHE, 2018) for future analysis. A principal component analysis will be carried out to determine dietary patterns associated with obesity.

Descriptive statistics will be used to look at the general distributions and quality of the data collected. Likert (5-point) ordinal scale data will be displayed by clustered bar charts. The $\mathrm{Chi}^{2}$ test and independent t-test will be used for comparison between ethnicity (African vs Caribbean) and categorical (percent, \%) and continuous (means) normally distributed variables, respectively. Mann-Whitney U-test will be performed for comparing medians of non-parametric variables.

Simple linear and logistic regressions will be used to explore factors associated with higher BMI (continuous variable) and overweight/obesity (BMI $\geq 25 / 30 \mathrm{~kg} / \mathrm{m}^{2}$ ). Multiple linear and logistic regression will be used to test whether individual variables are independently predictive of BMI and overweight/obesity, respectively. Other outcomes such as waist circumference, waist-to-hip ratio, and \%BF will also be explored. Statistical analysis will be performed using SPSS 24 (SPSS, 2016).

\section{Discussion}

Little is known about diet-related lifestyle choices in the BME communities or factors influencing such decisions. Current acculturation among BME women and attitudes to diet, lifestyle and body image research is limited to certain ethnic groups. A need is evident to broaden the research to include the experiences of those who have also shown changes in 
body image and eating behaviour post-migration, such as AfC groups (Gramaglia, Delicato, \& Zeppegno, 2018). This study will enable better elucidation of the relationships between dietary and biologic variables, as well as behavioural and attitudinal issues underpinning the nutritional and health status of the AfC migrant population in the UK. Consequently, this study will assist in translating epidemiological knowledge into future preventive actions.

To design responsive interventions, a first step is to understand contextual influences and determinants of behaviour. A quantitive study is well-placed to collect data on factors influencing behaviour. Understanding these influences will inform the theory underpinning intervention design to support these women. Theoretical underpinned interventions are more effective than those purely empirically designed (Fernandez et al., 2019). Furthermore, this study will provide a detailed assessment of the role of cultural/ traditional foods in the diets of these communities and present nutritional information. This may guide health-care practitioners in individualising their care for service users from these communities and enabling identification of types of foods that might need to be targeted or encouraged in advising patients on dietary modifications. Ultimately, the findings may enable care to be more culturally tailored (Di Noia, Furst, Park, \& Byrd-Bredbenner, 2013).

\section{Strengths and limitations}

The majority of participants completed a self-administrated online survey. However, participants were given an opportunity to use a paper-based format and assisted interview. It is known that the mode of questionnaire administration can have an impact on data quality. Within any mode of administration, there are a number of potential factors (e.g. wording, question order, response format, questionnaire layout) acting at different levels, which could also influence responses making it difficult to isolate the effects of each factor on the accuracy of the data collected (Bowling, 2005). Computerized self-administration methods may place a cognitive and literacy burden on participants compared to face-to-face interviews. (Bowling, Bond, Jenkinson, \& Lamping, 1999) However, face-to-face interviews can yield an excess of positive responses, 'yes-saying' or acceptance and social desirability biases, compared to self-administration mode, due to the fact that it is perceived to be 'easier' to agree than disagree with others (Bowling, 2005). Some people also tend to respond to certain questions in a way they perceive they should respond. 'Yes-saying' can also be frequent on self-administered questionnaires; however, it seems to be less evident than in interviews. Computer-based and self-administration methods can potentially slow down the pace of the interview, allowing participants more time to think, thus providing more accurate responses. However, if a particular question is misread or misunderstood, the results could be skewed.

This study applies a more meaningful classification of ethnicity compared to the previous studies (Gilbert \& Khokhar, 2008) in which no distinction is made between Black Africans, Black Carribeans and other Black groups. In the design of the current study, ethnicity was self-ascribed and also confirmed by parental and grandparental country of birth. Questions on cultural identity, languages spoke at home and religious affiliation were also included, as it is recommended that ethnicity should reflect a way of grouping individuals with some shared identity, including, but not restricted to, place of birth, religion, language, cultural practices and traditions, and common geographical origins (Phinney, 1992).

While multiple recalls using triple-pass methodology has a number of advantages over other methods of dietary assessment, all methods have limitations (Nightingale et al., 2016; Vucic 
et al., 2009). In this case, the method is dependent upon the participant's ability to recall intake accurately and there are possible recall biases, as with all self-report methods. Although using photographic food atlas illustrating a range of portion sizes for different types of meals is a useful tool for portion size estimation, the risk of over- or underestimation is not completely eliminated. Participants' age and BMI are commonly reported factors influencing the estimation of food consumption when using food photographs (Nelson, Atkinson, \& Darbyshire, 1996). Additionally, since the research team comprised of both Caucasian and AfC researchers, it is possible that the non-concordant ethnicity of some researchers may influence the accuracy of the data collected. The impact of this was minimised by all researchers being familiar with cultural foods and slang/common names reassuring participants that the research team had this knowledge.

\section{Conclusions}

Despite its limitations, the ATTITUDE study is novel in that it focuses on exploring the attitudes and determinants of diet, lifestyle and health behaviour of women in both African and Caribbean populations. Understanding the motivations and beliefs of our ethnic communities can help to improve the salience of healthcare offered. The ATTITUDE study could then provide a "road map" for how future tailored interventions might be designed. 


\section{References}

Amorim, A. R., Rössner, S., Neovius, M., Lourenço, P. M., \& Linné, Y. (2007). Does excess pregnancy weight gain constitute a major risk for increasing long-term BMI? Obesity, 15(5). https://doi.org/10.1038/oby.2007.149

Archibald, C. (2011). Cultural tailoring for an Afro-Caribbean community: a naturalistic approach. Journal of Cultural Diversity, 18(4), 114-119. Retrieved from http://www.ncbi.nlm.nih.gov/pubmed/22288207

Bartlett II, J. E., Kotrlik, J. W., \& Higgins, C. C. (2001). Determing Appropriate Sample Size in Survey Research. Information Technology, Learning, and Performance Journal, 19(1), 43-50.

Berge, J., Larson, N., Bauer, K., \& Neumark-Sztainer, D. (2011). Are parents of young children practicing healthy nutrition and physical activity behaviors?. Pediatrics, 127(5), 881-887.

Bhuiyan, A. R. (2003). Differences in Body Shape Representations among Young Adults from a Biracial (Black-White), Semirural Community: The Bogalusa Heart Study. American Journal of Epidemiology, 158(8), 792-797. https://doi.org/10.1093/aje/kwg218

Blissett, J., \& Bennett, C. (2013). Cultural differences in parental feeding practices and children's eating behaviours and their relationships with child BMI: A comparison of Black Afro-Caribbean, White British and White German samples. European Journal of Clinical Nutrition, 67(2), 180-184. https://doi.org/10.1038/ejcn.2012.198

Bowling, A. (2005). Mode of questionnaire administration can have serious effects on data quality. Journal of Public Health, 27(3), 281-291. https://doi.org/10.1093/pubmed/fdi031

Bowling, A., Bond, M., Jenkinson, C., \& Lamping, D. (1999). Short Form 36 (SF-36) Health Survey questionnaire: which normative data should be used? Comparisons between the norms provided by the Omnibus Survey in Britain, the Health Survey for England and the Oxford Healthy Life Survey. Journal of Public Health, 21(3), 255-270. https://doi.org/10.1093/pubmed/21.3.255

Centres for Disease Control and Prevention. (2007). Anthropometry procedures manual. National Health and Nutrition Examinatory Survey (NHANES).

Chowbey, P., \& Harrop, D. (2016). Healthy eating in UK minority ethnic households : influences and way forward. In Better Health Briefing Paper 42. Retrieved from http://shura.shu.ac.uk/12926/

Di Noia, J., Furst, G., Park, K., \& Byrd-Bredbenner, C. (2013). Designing culturally sensitive dietary interventions for African Americans: review and recommendations. Nutrition Reviews, 71(4), 224-238. https://doi.org/10.1111/nure.12009

Fernandez, M. E., Ruiter, R. A. C., Markham, C. M., \& Kok, G. (2019). Intervention Mapping: Theory- and Evidence-Based Health Promotion Program Planning: Perspective and Examples. Frontiers in Public Health, 7. https://doi.org/10.3389/fpubh.2019.00209

Frankenfield, D., Roth-Yousey, L., \& Compher, C. (2005). Comparison of predictive equations for resting metabolic rate in healthy nonobese and obese adults: a systematic 
review. Journal of the American Dietetic Association, 105(5), 775-789. https://doi.org/S0002822305001495 [pii]10.1016/j.jada.2005.02.005

Gatineau, M., \& Mathrani, S. (2011). Ethnicity and obesity in the UK. Perspectives in Public Health, Vol. 131, pp. 159-160. https://doi.org/10.1177/1757913911412478

Gibson, L. Y., Byrne, S. M., Davis, E. A., Blair, E., Jacoby, P., \& Zubrick, S. R. (2007). The role of family and maternal factors in childhood obesity. Medical Journal of Australia, 186(11), 591-595. https://doi.org/10.1007/s10567-010-0073-0.The

Gilbert, P. A., \& Khokhar, S. (2008). Changing dietary habits of ethnic groups in Europe and implications for health. Nutrition Reviews, 66(4), 203-215. https://doi.org/10.1111/j.1753-4887.2008.00025.x

Goff, L. M., Timbers, L., Style, H., \& Knight, A. (2015). Dietary intake in Black British adults; An observational assessment of nutritional composition and the role of traditional foods in UK Caribbean and West African diets. Public Health Nutrition, 18(12), 21912201. https://doi.org/10.1017/S1368980014002584

Gramaglia, C., Delicato, C., \& Zeppegno, P. (2018). Body Image, Eating, and Weight. Some Cultural Differences. In Body Image, Eating, and Weight (pp. 427-439). https://doi.org/10.1007/978-3-319-90817-5_31

Holdsworth, M., Delpeuch, F., Landais, E., Gartner, A., Eymard-Duvernay, S., \& Maire, B. (2006). Knowledge of dietary and behaviour-related determinants of non-communicable disease in urban Senegalese women. Public Health Nutrition, 9(08), 975. https://doi.org/10.1017/PHN2006979

Holdsworth, M., Gartner, A., Landais, E., Maire, B., \& Delpeuch, F. (2004). Perceptions of healthy and desirable body size in urban Senegalese women. International Journal of Obesity, 28(12), 1561-1568. https://doi.org/10.1038/sj.ijo.0802739

Howard, N. J., Hugo, G. J., Taylor, A. W., \& Wilson, D. H. (2008). Our perception of weight: Socioeconomic and sociocultural explanations. Obesity Research \& Clinical Practice, 2(2), 125-131. https://doi.org/10.1016/j.orcp.2008.03.003

HSE. (2006). Health Survey for England - 2004, Health of Ethnic Minorities, Main report.

Joo, J. Y., \& Liu, M. F. (2019). Experience of Culturally-Tailored Diabetes Interventions for Ethnic Minorities: A Qualitative Systematic Review. Clinical Nursing Research, 105477381988595. https://doi.org/10.1177/1054773819885952

Leung, G., \& Stanner, S. (2011). Diets of minority ethnic groups in the UK: Influence on chronic disease risk and implications for prevention. Nutrition Bulletin, 36(2), 161-198. https://doi.org/10.1111/j.1467-3010.2011.01889.x

Meng, L., Zhao, D., Pan, Y., Ding, W., Wei, Q., Li, H., ... Mi, J. (2016). Validation of Omron HBP-1300 professional blood pressure monitor based on auscultation in children and adults. BMC Cardiovascular Disorders, 16(1), 9. https://doi.org/10.1186/s12872015-0177-z

Nelson, M., Atkinson, M., \& Darbyshire, S. (1996). Food photography II: use of food photographs for estimating portion size and the nutrient content of meals. British Journal of Nutrition, 76(1), 31-49. https://doi.org/10.1079/BJN19960007

Nelson, M., Atkinson, M., \& Meyer, J. (1997). A Photographic Atlas of Food Portion Sizes (Food Standards Agency, Ed.). London.

Nelson, M., Holmes, B., \& Roberts, C. (2013). Dietary Assessment: Recalls. Retrieved from http://www.dapa-toolkit.mrc.ac.uk/dietary-assessment/methods/recalls/index.php 
Nightingale, H., Walsh, K. J., Olupot-Olupot, P., Engoru, C., Ssenyondo, T., Nteziyaremye, J., ... Maitland, K. (2016). Validation of triple pass 24-hour dietary recall in Ugandan children by simultaneous weighed food assessment. BMC Nutrition. https://doi.org/10.1186/s40795-016-0092-4

Nutrics. (2018). Research Edition (V5.02) [computer software]. Retrieved from www.nutritics.com

ONS. (2012). Ethnicity and National Identity in England and Wales 2011: Office for National Statistics.

PHE. (2018). The 2018 review of the UK Nutrient Profiling Model. Retrieved from https://assets.publishing.service.gov.uk/government/uploads/system/uploads/attachment _data/file/694145/Annex_A_the_2018_review_of_the_UK_nutrient_profiling_model.p $\mathrm{df}$

Phinney, J. S. (1992). The Multigroup Ethnic Identity Measure. Journal of Adolescent Research, 7(2), 156-176. https://doi.org/10.1177/074355489272003

Siega-Riz, A. M., Herring, A. H., Carrier, K., Evenson, K. R., Dole, N., \& Deierlein, A. (2010). Sociodemographic, perinatal, behavioral, and psychosocial predictors of weight retention at 3 and 12 months postpartum. Obesity (Silver Spring), 18(10), 1996-2003. https://doi.org/10.1038/oby.2009.458

Smith, N. R., Kelly, Y. J., \& Nazroo, J. Y. (2012). The effects of acculturation on obesity rates in ethnic minorities in England: Evidence from the Health Survey for England. European Journal of Public Health, 22(4), 508-513. https://doi.org/10.1093/eurpub/ckr070

SPSS. (2016). Statistical Package for Social Scientists. IBM SPSS Statistics for Windows. Version 24. NY: IBM corp.

Stadlmayr, B., Charrondiere, U. R., Enujiugha, V. N., Bayili, R. G., Fagbohoun, E. G., Samb, B., ... Burlingame, B. (2012). West African Food Composition Table. In Food and Agriculture Organization (FAO) of the United Nations. https://doi.org/978-92-5007207-4

Szczepura, A. (2005). Access to health care for ethnic minority populations. Postgraduate Medical Journal, 81(953), 141-147. Retrieved from http://wrap.warwick.ac.uk/99/1/WRAP_Szczepura_zAccess_Paper_Review_Revised_S end.doc

Vucic, V., Glibetic, M., Novakovic, R., Ngo, J., Ristic-Medic, D., Tepsic, J., ... Gurinovic, M. (2009). Dietary assessment methods used for low-income populations in food consumption surveys: a literature review. British Journal of Nutrition, 101(S2), S95S101. https://doi.org/10.1017/S0007114509990626 